\title{
Možnost za uporabo standarda ISO 9001 v izobraževalnih organizacijah
}

Lijana Kunc
Peter Kunc

\section{Po podatkih Zavoda Republike Slovenije za statistiko je $v$ Sloveniji uradno registriranih samo 686 organizacij (d. o. o. in drugih), zajetih v sklopu »drugo izobraževanje«, kamor sodita tudi računalniško in jezikovno izobraževanje kot dve v javnih občilih najpogosteje reklamirani izobraževanji.}

Vse te organizacije se bodo prej ali slej (ali pa so se že) srečale s problematiko obvladovanja kakovosti njihovih storitev, ki naj bi bila glavna skrb vsake organizacije. Tako se bodo srečale tudi s standardom ISO 9001, o katerem bomo govorili v osrednjem delu tega članka.

Da bi bila organizacija uspešna, mora omogočati storitve, ki:

a) izpolnjujejo dobro opredeljene potrebe, uporabo ali namen;

b) zadovoljujejo uporabnikova pričakovanja;

c) so skladne $\mathrm{z}$ določenimi standardi in s specifikacijami;

d) izpolnjujejo pravne in druge družbene potrebe;

e) so dostopne po konkurenčnih cenah;

f) pri upoštevanju stroškov prinašajo dobiček.

Da bi organizacija dosegla svoje cilje, jo je treba organizirati tako, da obvladuje tehnične, administrativne in človeške dejavnike, ki vplivajo na kakovost storitev. Vse to obvladovanje mora biti usmerjeno v zmanjševanje, odpravljanje in, kar je najpomembnejše, $v$ preprečevanje pomanjkljivosti $v$ kakovosti.

Da bi dosegli cilje, zastavljene $\mathrm{v}$ politiki kakovosti organizacije, je treba razviti in izvajati sistem kakovosti (sistem kakovosti je sistem obvladovanja poslovanja organizacije).

Da bi dosegli čim večjo učinkovitost in zadovoljili pričakovanja kupcev, je bistveno, da sistem kakovosti ustreza vrsti dejavnosti in storitvam, ki jih organizacija ponuja.

Sistem kakovosti ima dva med seboj povezana vidika:

a) potrebe in interese podjetja; poslovna potreba podjetja je doseči in vzdrževati željeno kakovost z optimalnimi stroški. Izpolnjevanje tega vidika kakovosti je povezano $\mathrm{z}$ načrtovano in učinkovito uporabo tehnoloških, človeških in materialnih virov, dostopnih podjetju.

b) kupčeve potrebe in pričakovanja; kupčeva potreba je zaupanje v sposobnost podjetja, da omogoča želeno kakovost in jo tudi stalno vzdržuje.

O takih sistemih kakovosti govorimo v zvezi s standardi skupine ISO 9000. To so standardi, ki podajajo zahteve za sisteme kakovosti in vodila za uporabo sistema v različnih organizacijah. $\mathrm{V}$ standardih niso podrobno določeni načini vodenja kakovosti, temveč so podani zgolj okvirno. Vsaka organizacija ima tako veliko možnosti za lastne rešitve.
Da bi na SIQ (Slovenski inštitut za kakovost in meroslovje) pomagali omenjeni množici izobraževalnih organizacij pri njihovih prizadevanjih za kakovost, smo pripravili Vodilo za uporabo standarda ISO 9001 (1994) v organizacijah s področja izobraževanja. $\mathrm{V}$ njem so zahteve omenjenega standarda $\mathrm{v}$ jeziku »izobraževalcev«. Standard ISO 9001 in drugi standardi iz skupine ISO 9000 so namreč kljub že opravljenim spremembam še vedno preveč prilagojeni podjetjem, ki proizvajajo, in veliko manj tistim, ki ponujajo splošne storitve, zlasti izobraževalne.

\section{Sistem kakovosti in zahteve standarda 1509001}

V standardu ISO 9001, ki podaja zahteve za sistem kakovosti in pomeni tudi osnovo za kasnejše certificiranje, so te zahteve po mnenju večine uporabnikov standarda po posameznih točkah precej nepregledno navedene. Zato si pred podrobnejšim pregledom zahtev najprej poglejmo splošen prikaz aktivnosti, ki se izvajajo $\mathrm{v}$ organizaciji.

$\mathrm{V}$ organizaciji poteka osnovni poslovni proces, ki se začne in konča s stiki s kupcem. Osnovni proces ne more potekati, če niso na voljo ustrezni viri (materialni, finančni, kadrovski, informacije) in primerne podporne aktivnosti. Da organizacija deluje, pa je potrebno ustrezno vodenje.

Prikaz strukture organizacije in skupin aktivnosti

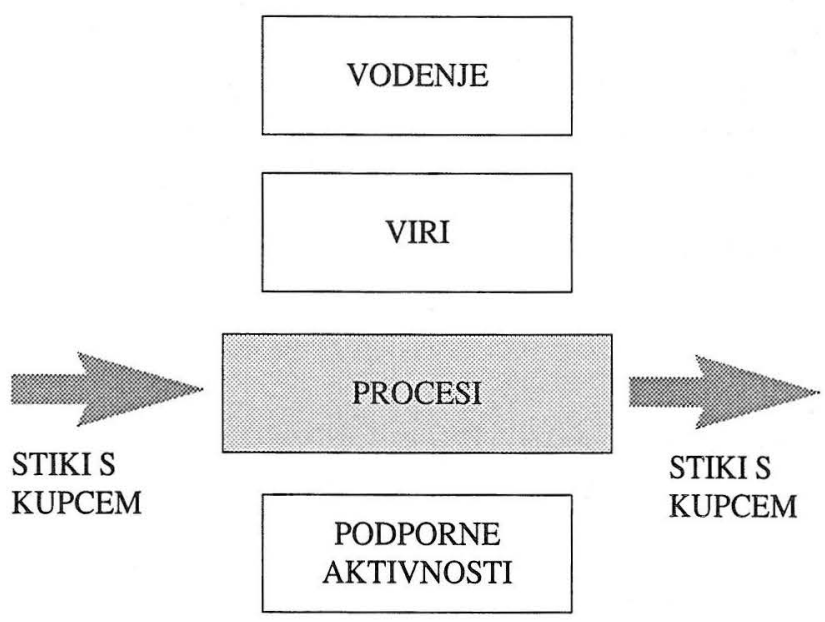


O navedenih aktivnostih bomo govorili v naslednjih točkah standarda ISO 9001 (1994):

Vodenje

Odgovornost vodstva (4.1)

Sistem kakovosti (4.2)

Korektivni in preventivni ukrepi (4.14)

Interna presoja (4.17)

Viri

Obvladovanje dokumentov in podatkov (4.5)

Obvladovanje zapisov o kakovosti (4.16)

Usposabljanje (4.18)

Odgovornost vodstva (delno) (4.1)

Stiki s kupcem

Pregled pogodbe (4.3)

Servisiranje (4.19)

\section{Osnovni proces}

Obvladovanje razvoja (4.4)

Obvladovanje procesa (4.9)

Obvladovanje neskladnih proizvodov (4.13)

Ravnanje, skladiščenje, zavijanje, zaščita in odprema (4.15)

\section{Podpome alktivnosti}

Nabava (4.6)

Proizvodi, ki jih dobavlja kupec (4.7)

Prepoznavanje in sledljivost proizvodov (4.8)

Kontrola in preskušanje (4.10)

Kontrolna, merilna in preskusna oprema (4.11)

Status kontroliranja in preskušanja (4.12)

Statistične metode (4.20)

Razprava o tem, ali morda ne spada točka 4.6 Nabava med »vire« (in podobno) je seveda možna, vendar ni bistvena pri razumevanju organizacije kot celote, kot mreže številnih različnih procesov.

\section{Odgovornost vodstva (4.1)}

\section{Politika kakovosti}

Pojem »politika kakovosti« lahko razdelimo na dva dela: politiko in kakovost. Kakovost lahko razlagamo kot »izpolnjevanje zahtev«. Te zahteve so cilji, ki jih organizacija želi doseči. Pri tem mora upoštevati tudi pričakovanja in potrebe svojih kupcev. V našem primeru so ti kupci tisti, ki plačajo izobraževalne storitve. Cilje, ki morajo biti merljivi, da lahko ocenjujemo njihovo uresničevanje, določi vodstvo, ki v organizaciji odloča. Pojem "politika« pa lahko v slovenščino prevajamo tudi kot »načela«.

Če torej znova združimo oba dela pojma »politika kakovosti«, ugotovimo, da mora omenjeno vodstvo določiti načela oziroma način, $s$ katerimi bo poskušalo doseči zastavljene cilje.

»Cilji« so v izobraževalni organizaciji lahko na primer:

- povprečna letna ocena vseh tečajev nad 8,5 (od 10);

- zvišanje povprečne letne ocene $\mathrm{v}$ naslednjih petih letih $\mathrm{s}$ sedanjih 7,3 na 8,6;

- znižanje števila pritožb udeležencev na tečajih v naslednjih treh letih s sedanjih 50 na leto na 5 na leto.

\section{Organizacija}

Organiziranost mora biti jasno določena. »Organiziranost« pomeni, da vsi vedo, kaj kdo dela. Določene morajo biti torej odgovornosti, pooblastila in medsebojni odnosi zaposlenih. Pri določanju organiziranosti si pomagamo $\mathrm{z}$ različnimi diagrami (organizacijska shema, diagrami poteka itd.), lahko tudi z matriko odgovornosti. Tudi v opisih delovnih postopkov in v podobnih dokumentih morajo biti nedvoumno in konkretno (delovna mesta, funkcije) določene odgovornosti za posamezne aktivnosti.

Vodstvo organizacije mora med svojimi člani določiti tako imenovanega predstavnika vodstva, ki mora imeti, ne glede na druge odgovornosti, določena pooblastila za:

a) zagotavljanje, da je sistem kakovosti vzpostavljen, da ga izvajajo in vzdržujejo v skladu s standardom;

b) poročanje o delovanju sistema kakovosti vodstvu, za pregled in kot osnovo za izboljšanje sistema kakovosti.

Predstavnik vodstva naj bo oseba, ki celovito razume dejavnost organizacije ter sistem kakovosti. Izmed članov vodstva mora biti eden z izvršilno odgovornostjo zato, da lahko sodeluje pri odločanju.

\section{Pregled, ki ga zahteva vodstvo}

Namen pregleda, ki ga zahteva vodstvo, je oceniti izvajanje politike kakovosti in doseganje postavljenih ciljev ter ustrezno ukrepati. Pregled praviloma izvajajo enkrat letno, zadeve pa obravnavajo bolj globalno; v nasprotju od rednega tedenskega ali mesečnega spremljanja dogajanja v organizaciji, ki je praviloma posvečeno reševanju sprotne problematike in usklajevanju aktivnosti.

\section{Sistem kakovosti (4.2)}

Tipična oblika dokumentiranosti sistema kakovosti je poslovnik kakovosti, ki povzema individualni pristop organizacije $\mathrm{k}$ zahtevam za sistem kakovosti. Če so potrebni še dodatni dokumenti (opisi postopkov, navodilo za delo, obrazci), ki niso vključeni v poslovnik, se v njem nanje sklicuje ter jih navaja kot referenčne dokumente.

Obseg dokumentacije naj bo racionalen - ne preveč in ne premalo dokumentov. Zapisano naj bo tisto, kar se zaposlenim zdi pomembno, da bi morali enako izvajati tudi ob morebitnih kadrovskih spremembah.

Osnovno vodilo pri dokumentiranju dejanskega načina dela (in ne želja za prihodnost) naj bodo vprašanja: kdo, kdaj, kaj, kako dela.

\section{Pregled pogodbe (4.3)}

»Pregled pogodbe« označuje aktivnosti, ki jih organizacija izvaja, da bi ugotovila, če je sposobna izpolniti zahteve kupca. Da je ocena sposobnosti (primerjava s sposobnostmi organizacije) sploh možna, morajo biti zahteve določene in dokumentirane.

Za »pogodbo« ne smemo šteti zgolj dokumente, ki jih imenujemo pogodbe, temveč tudi naročila, ki so v izobraževalnih organizacijah pravzaprav »prijava«, »vpis« in podobno.

Faza »pregleda pogodbe« zajema predvpisno obdobje in postopek vpisa. Zato je treba dokumentirati oboje: obvladovanje marketinškega gradiva in prospektov in postopek sprejema prijave oziroma postopek vpisa.

\section{Obvladovanje razvoja (4.4)}

»Razvoj« pomeni v izobraževalni organizaciji razvoj novih programov. Celotni postopek razvoja programov mora biti dokumentiran. Že sami naslovi podtočk standarda jasno nakazujejo aktivnosti, ki jih je pri tem treba izvajati:

- identifikacija in dokumentiranje vhodnih zahtev; 
- načrtovanje razvoja (aktivnosti, nosilci, roki);

- izvajanje aktivnosti, skupaj z občasnimi pregledi vmesnih rezultatov razvoja (pri krajših razvojnih nalogah to najbrž niti ni potrebno):

- dokumentiranje rezultatov razvoja;

- verifikacija in validacija razvoja.

Sami postopki sprememb naj bodo predmet rednega pregleda.

\section{Obvladovanje dokumentov in podatkov $(4.5)$}

Obvladovanje dokumentov zagotavlja, da so na voljo natančni ažurni dokumenti, ki so potrebni za izpolnitev zahtev. To velja za dokumente, ki so na papirju ali shranjeni v elektronskem mediju.

Dokumenti, ki jih je treba obvladovati, so interni in tudi eksterni.

Nekaj primerov obvladovanih dokumentov:

interni

- poslovnik kakovosti,

- navodila za delo,

- urniki,

- izpitni postopki/postopki ocenjevanja,

- informacije o programu,

- predpisi, ki se nanašajo na varnost učencev ali druge veljavne zakonske zahteve, ki jih je treba izpolnjevati, $\mathrm{ki}$,

- seznam bistvenih priročnikov organizacije in hišni priročni-

- zapisi (podatki) o učencih in osebju so prav tako pomembni interni zapisi, ki morajo biti popolni in ažurni;

eksterni

- zadevna zakonodaja,

- vladne okrožnice,

- predpisi zunanjih izpitnih teles,

- predpisane vsebine tečajev.

Način obvladovanja dokumentov se v izobraževalnih organizacijah ne razlikuje od načina $\mathrm{v}$ drugih organizacijah. Ker so tudi zahteve v tej točki dovolj jasne, menimo, da ne potrebujejo posebne razlage pri izobraževanju.

\section{Nabava (4.6)}

Organizacija naj jasno določi, kdo je odgovoren in pooblaščen za nabavo specificiranih storitev in materialov, katerih neskladnost bi materialno vplivala na sposobnost organizacije pri izpolnjevanju njene lastne zahteve. Naročila, ki morajo biti pisna, morajo popolnoma opredeliti naročeno storitev ali material.

$\mathrm{Z}$ opredeljenimi in dokumentiranimi postopki nabave in izbire tistih, pri katerih se nabavlja (podpogodbeniki), se poskuša zagotoviti, da so materiali in storitve, ki lahko bistveno vplivajo na proces usposabljanja, nabavljeni od odobrenih podpogodbenikov, izbranih na osnovi njihove sposobnosti za izpolnitev te zahteve.

Bistven element pri izobraževanju, ki se ga »nabavlja«, je strokovno osebje - podpogodbeni predavatelji, inštruktorji, učitelji, asistenti, organizacije za izobraževanje in usposabljanje. Nabavljamo pa lahko tudi:

- učne materiale,

- računalniško programsko in strojno opremo,
- laboratorijske naprave,

- organizatorje in izvajalce delovne prakse (omogočanje razmer, izvajalcev),

- podpogodbeno usposabljanje,

- prostor, v katerem izvajamo izobraževanje,

- gostinske storitve itd.

\section{Proizvodi, ki jih dobavi kupec (4.7)}

Ta točka se nanaša predvsem na primere, pri katerih se izvaja izobraževanje zunaj prostorov organizacije, kadar naročnik zagotovi prostor in opremo, na primer predavalnice ipd. Možnih je še veliko drugih primerov, kot na primer, da v skladu s pogodbo kupec preskrbi materiale, dokumentacijo, prostore, osebje in druge storitve izobraževanja in usposabljanja. Če organizacija dopušča take primere, mora imeti sistem, s katerim ugotovi, ali so taki materiali in storitve primerni in se skladajo $\mathrm{z}$ zahtevami programa ali pa da se nasprotno uskladijo $\mathrm{z}$ zahtevami.

\section{Prepoznavanje in sledlipost proizvodov (4.8)}

$\mathrm{S}$ »proizvodom « v tej zvezi mislimo na programe in elemente programov. Dani naj jim bodo jasni, natančni naslovi ali številke, ki se dosledno uporabljajo navznoter in navzven. Druge pomembne zadeve $v$ tem smislu bi bili na primer zapisi o slušateljih/tečajnikih, predavateljih, udeleženih v določenem programu.

\section{Obvladovanje procesa $(4.9)$}

Obvladovanje procesa pomeni pri izobraževanju izvedba kurikuluma (kurikulum je sistematični prikaz nameravanega učnega procesa $v$ določenem obdobju). $\mathrm{Z}$ njim naj bi pouk čim bolj kakovostno pripravili, uresničevali in ovrednotili v skladu s postavljenimi cilji.

Za vsak kurikulum naj organizacija do podrobnosti določi oziroma načrtuje:

1. Cilj predmeta (globalni in etapni).

2. Vsebino, razčlenitev po posameznih temah in njihovo razvrstitev v primerno zaporedje.

3. Metode in oblike dela (pri katerih ima učenec različne možnosti, te naj bodo jasno dokumentirane, npr. tečaj, individualno delo, študij ob/iz dela). Organizacija naj vodi evidenco o razlogih za izbor določenih izvedbenih metod za vsak učni program (točka 4.4). Obstajajo naj dokazi, da je bila učenčeva izbira možnosti primerno vodena (postopki za izbiro, zapisovanje odločitev in preverjanje, da so odločitve učenca skladne s cilji organizacije).

4. Literaturo.

5. Učne pripomočke in sredstva.

6. Ocenjevanje učnih učinkov. To naj bo veljavno (validno), zanesljivo, objektivno, občutljivo in tudi ekonomično. Organizacija naj ima jasno določene in dokumentirane postopke za ocenjevanje. Taki postopki naj poleg naštetih zahtev vključujejo tudi inštrumente ocenjevanja, izpitne metode, dogovore glede varnosti, pregled izpitov in pisnih nalog, urnik izpitov itd.

\section{Kontrola in preskušanje (4.10)}

Preskušanje in testiranje izdelka je pri izobraževanju analogno stalnemu, sistematičnemu ocenjevanju študijskega procesa kot 
sistema, v vseh njegovih fazah, ki daje dogovorjeno storitev. Z ocenjevanjem zbiramo podatke za vodenje izobraževalnega procesa, za povečevanje njegove uspešnosti ter za ugotavljanje, kako dosegamo postavljene cilje.

Predmeti ocenjevanja so lahko različni: delo učenca/učitelja, dejavnost organizacijske enote, uresničevanje sprejetega delovnega programa, ocena kakovosti dela, pregled opravljenih obveznosti učencev/učiteljev, analiza osipa, ocena rezultatov in metod preverjanja znanja učencev, uvajanje sodobnih učnih metod $\mathrm{v}$ izobraževalni proces, predlogi ukrepov za izboljšanje itd.

Izvajalci ocenjevanja so lahko: učenci, učitelji, razna delovna telesa itd.

Postopki, metode, sredstva in časovni intervali ocenjevanja so odvisni od vrste in namena vrednotenja. To so lahko: testi znanja, izpitna vprašanja, ankete, prisotnostne liste, statistični vprašalniki itd.

\section{Kontrolna, merilna in preskusna oprema (4.11)}

Ta točka standarda od organizacije zahteva obvladovanje opreme, s katero se dokazuje skladnost z zahtevami. Primeri »opreme« v izobraževalni organizaciji so naslednji:

- učna priložnost, zunanje ocenjevanje;

- veljavne metode ocenjevanja;

- kvalifikacije predavateljev/učiteljev, ocenjene glede na sprejete standarde v državi;

- validacija tehnik opazovanja (npr. dosleden), povratni vprašalnik.

\section{Stałus kontroliranja in preskušanja (4.12)}

Možnost aplikacije zahtev iz te točke pri izobraževanju je vprašljiva ali pa vsaj zelo omejena.

\section{Obvladovanje neskladnih proizvodov $(4.13)$}

Neskladen je lahko:

- program,

- učenčevo znanje,

- nabavljeno gradivo,

- nabavljena storitev.

Če ugotovimo neskladnost, je treba ukrepati.

Učencu lahko na primer: $\mathrm{ka}$;

a) dovolimo ponavljanje testa ali ponovno predložitev izdel-

b) dovolimo nadaljevanje izobraževanja na osnovi predavateljevega dovoljenja;

c) učenca lahko preusmerimo na drug program;

c) od njega lahko zahtevamo, da opusti izobraževanje.

\section{Korektivni in preventivni ukrepi (4.14)}

Pojma preventivni in korektivni ukrepi sta že sama po sebi dokaj razumljiva. Bistvena razlika med njima je $v$ tem, da preventivno ukrepamo, da ne bi prišlo do neskladnosti, korektivno pa zato, ker je do neskladnosti prišlo in da se ne bi več ponovila.

Možni viri informacij za korektivno ukrepanje:
- pritožbe kupcev;

- pripombe učencev;

- rezultati presoj;

- interno ugotovljene neskladnosti (na primer problemi z urnikom, dvojna rezervacija predavalnice, nepopolno ali nenatančno ocenjevanje);

- delež neuspešnih oziroma uspešnih učencev.

Primer preventivnega ukrepanja je lahko analiza celotnega poslovnega procesa ali pa samo izobraževalnega procesa, $\mathrm{z}$ njim naj bi ugotovili možne neskladnosti in preprečili, da bi do njih prišlo.

\section{Ravnanje, skladiščenje, zavijanje, zaščiła in odprema (4.15)}

Zahteve $\mathrm{v}$ tej točki bi se lahko nanašale na uporabo učnih sredstev in učnih pripomočkov, ki zahtevajo pazljivo ravnanje in skladiščenje. Za to je treba pripraviti ustrezne pisne postopke ali navodila.

\section{Obvladovanje zapisov o kakovosti (4.16)}

»Zapise o kakovosti« bi z drugimi besedami lahko poimenovali tudi zapise o izvajanju poslovnega procesa, nastajajo vsakodnevno kot posledica opravljenega dela. So osnova za analize o učinkovitosti delovanja sistema kakovosti in za ukrepanje za njegovo izboljšanje.

\section{Interna presoja $(4.17)$}

$\mathrm{Z}$ interno presojo ugotavljamo, ali aktivnosti, ki jih zajema sistem kakovosti, potekajo, kot je bilo dogovorjeno in dokumentirano.

\section{Usposablianje (4.18)}

Organizacija naj ima izdelane postopke za doseganje optimalne strukture osebja, $\mathrm{z}$ upoštevanjem individualnih interesov ter interesov organizacije. Postopki razvoja osebja naj vključujejo zbiranje informacij za potrebe razvoja, načrt in pripravo ustreznih ukrepov in realizacijo razvojnih načrtov.

\section{Servisiranje (4.19)}

Zahteva se nanaša na storitve, ki jih ponuja organizacija uporabnikom (učencem) še določen čas po tem, ko ti že končajo učni program.

Obstajati morajo postopki, ki opisujejo izvajanje teh storitev.

\section{Statistične mełode $(4.20)$}

Možnosti uporabe statističnih metod je več. Najpogosteje pa se uporabljajo pri analizah trendov sestavin kurikuluma.

Standard zahteva, da:

- najprej analiziramo možnost uporabe statističnih metod in to dokumentiramo;

- nato odločimo, katere metode in kje jih bomo uporabljali;

- pripravimo pisna navodila za uporabo izbranih metod;

- usposobimo osebje za uporabo izbranih metod. 


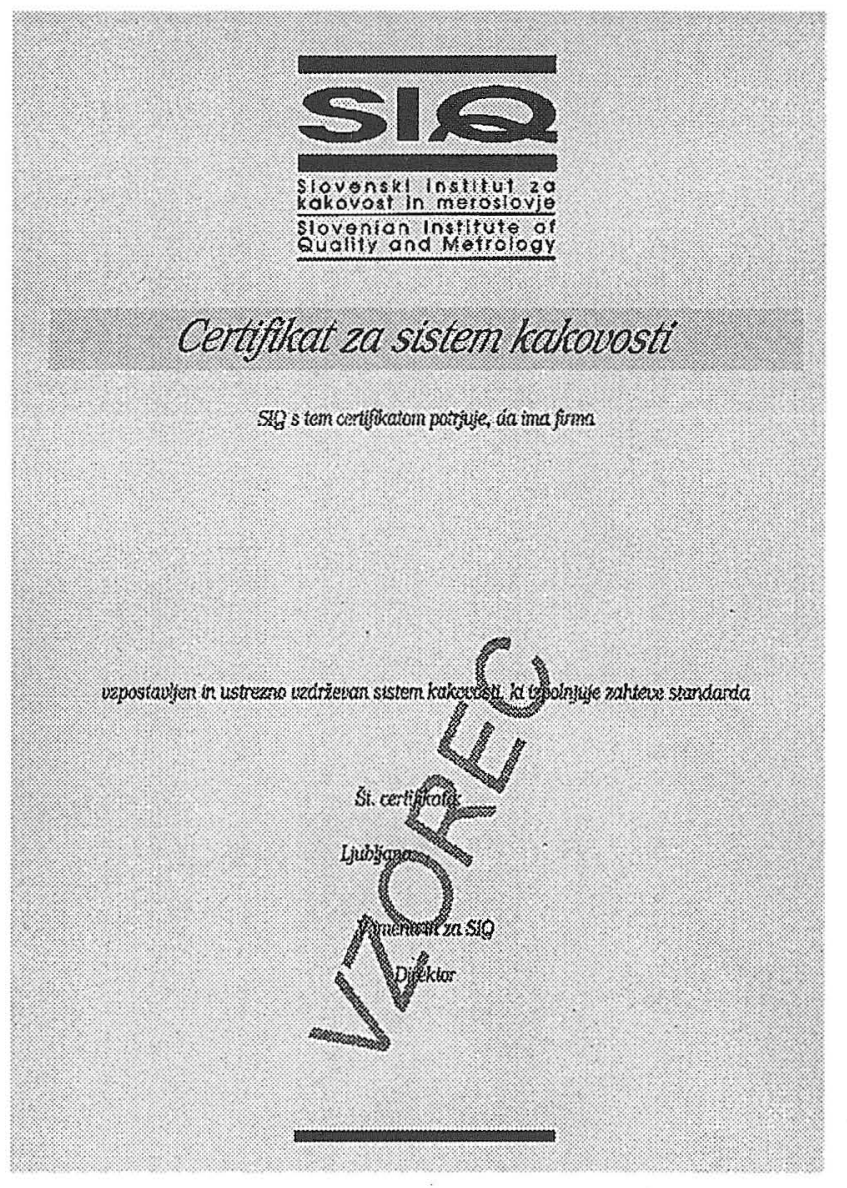

\section{Certifilkat za sistem kakovosti}

Pomen certifikata za sistem kakovosti bi lahko primerjali s spričevalom o uspešno opravljeni maturi. S certifikatom SIQ potrjuje Slovenski inštitut za kakovost in meroslovje, kot neodvisna in nepristranska institucija, da ima organizacija ustrezno vzpostavljen in vzdrževan sistem kakovosti, ki izpolnjuje zahteve na certifikatu navedenega standarda (na primer ISO 9001).

Velika večina podjetij se po vzpostavitvi sistema kakovosti odloči tudi za njegovo certificiranje. Sam postopek pridobitve certifikata pa poteka po naslednjih stopnjah.

1. Informativni razgovor: organizacija in SIQ izmenjata potrebne informacije pred začetkom certifikacijskega postopka.

2. Vloga: organizacija vloži pisni zahtevek za začetek certifikacijskega postopka, plača osnovno pristojbino ter izroči SIQ dokumente sistema kakovosti.

3. Presoja dokumentacije: SIQ oceni skladnost dokumentacije sistema kakovosti z zahtevami izbranega standarda.

4. Predpresoja: neobvezna, vendar koristna, pokaže na pomanjkljivosti v izvajanju sistema kakovosti.

5. Certifikacijska presoja: ugotavljanje skladnosti sistema kakovosti z zahtevami izbranega standarda, poročilo je osnova za sklepanje o podelitvi certifikata za sistem kakovosti.

6. Dodatna presoja: potrebna je, kadar pri certifikacijski presoji ugotovijo pomanjkljivosti ali kadar pride do sprememb v sistemu kakovosti že po podelitvi certifikata.

7. Redna presoja: enkrat na leto vljučuje ocenjevanje vzdrževanja sistema kakovosti.

Veljavnost certifikata ni časovno omejena. Certifikat velja, dokler podjetje izpolnjuje zahteve standarda in certifikacijskega pravilnika.

\section{Sklep}

Uporaba standard ISO $9001 \mathrm{v}$ izobraževalnih organizacijah je nedvomno možna. Prvo potrditev te trditve smo dobili že v stikih z uspešnejšimi tovrstnimi organizacijami v Sloveniji. Dokončna potrditev pa bodo izdani certifikati za sistem kakovosti. Upamo, da jih bodo prvič podelili še v letošnjem letu. Tako se bo krog panog - »uporabnikov« standardov in imetnikov SIQ certifikatov še bolj razširil.

\section{Lijana Kunc \\ vodja oddelka izobraževanja v podjetju Indos \\ Peter Kunc \\ vodja področja Ocenjevanje sistemov kakovosti pri SIQ - Slovenskem inštitutu za kakovost in meroslovje, Ljubljana}

\section{Viri}

ISO 9001 (1994).

SLS ISO 9004 (1992).

BS 5750 Guidance notes for application to education and training ( $1^{\text {st }}$ Edition, February 1991).

Guidelines on the application of ISO 9001 to further education and training (NACCB; Draft, March 1993).

Marentič-Požarnik, Barica: Prispevek k visokošolski didaktiki, 1978, Ljubljana, DZS.

SIQ Certifikacijski pravilnik za certificiranje sistemov kakovosti (izdaja 3/1995-01-25).

Vodilo za skupino standardov ISO 9000 (IKM, november 1992). 